\title{
Exploratory Laparotomy and Intestinal Resection in Children: Intraoperative Goal Directed Therapy and Intraoperative and Postoperative Outcomes
}

Claudine Kumba ( $\sim$ claudine.kumba@gmail.com )

Hôpital Universitaire Necker Enfants Malades, Assistance Publique Hôpitaux de Paris, APHP, Université de Paris

\section{Short Report}

Keywords: Exploratory laparotomy, intestinal resection, children, intraoperative and postoperative outcomes, intraoperative goaldirected therapies

Posted Date: August 6th, 2021

DOl: https://doi.org/10.21203/rs.3.rs-785514/v2

License: () This work is licensed under a Creative Commons Attribution 4.0 International License. Read Full License 


\section{Abstract}

Background: Reported independent predictors of intraoperative and postoperative complications were age, American Society of Anesthesiologists Score (ASA), emergency situations, surgery and transfusion. ASA was the independent predictor of mortality. We conducted a secondary analysis of the initial retrospective study in patients who underwent exploratory laparotomy and intestinal resection.

Objectives: To describe intraoperative and postoperative outcomes in patients who underwent exploratory laparotomy and intestinal resection in the initial study and to implement improvement protocols for intraoperative and postoperative optimization.

Methods: Secondary analysis of the initial study. The Ethics Committee approved the study.

Results: There were 54 patients with a median age of 15.5[0-172] months. Thirty-seven (68.5\%) patients underwent intestinal resection, nine (16.7\%) underwent exploratory laparotomy, and eight (16.8\%) underwent laparotomy for volvulus.

Fourteen $(25.9 \%)$ patients had intraoperative and/or postoperative complications. Two (3.7\%) patients had intraoperative hemorrhagic shock. Two (3.7\%) patients had postoperative cardio-circulatory failure. Three (5.6\%) had postoperative respiratory failure. One (1.8\%) patient had postoperative multiple organ failure and neurologic failure. Three (5.6\%) patients had postoperative abdominal sepsis. One (1.8\%) patient had postoperative multiple organ sepsis and neuromeningeal sepsis. Four (7.4\%) patients had postoperative pulmonary sepsis. Two (3.7\%) had postoperative septicemia. Six (11.1\%) patients had reoperations. Seventeen (31.5\%) patients had intraoperative transfusion. The in-hospital mortality rate was $3.7 \%$ in two patients.

Conclusion: Intraoperative goal-directed therapies need to be developed and included in these surgical settings for intraoperative and postoperative optimization.

\section{Introduction}

Intraoperative and postoperative outcomes in children have been reported to be multifactorial $(1,2,3,4)$. Reported independent predictors of intraoperative and postoperative complications were age, American Society of Anesthesiologists Score (ASA), emergency situations, surgery and transfusion $(1,2,3,4)$. ASA was the independent predictor of mortality (1).

Intraoperative and postoperative complications in pediatric surgical settings with regard to age have been described previously $(5,6,7,8,9,10)$. When considering the entire initial cohort of 594 patients, the overall rate of patients with intraoperative and/or postoperative complications was $23.9 \%$ (1). The most reported intraoperative complication was hemorrhagic shock, with an overall rate of $3.9 \%$ (1). The most commonly reported postoperative organ failure was neurologic, followed by respiratory, cardio-circulatory and multiple organ failure, with overall rates of $4.2,3.5,3$ and $1.5 \%$, respectively (1). The most commonly reported postoperative infection was septicemia, followed by pulmonary sepsis, abdominal sepsis, surgical wound sepsis and urinary sepsis, with overall rates of 3.7, 2.9, 2.7, 2 and 1.3\%, respectively (1). Overall transfusion rate was $49.2 \%$. Overall rate of reoperation was $7.2 \%$. The rate of emergency interventions was $22.9 \%$. Overall in-hospital mortality rate was $1.9 \%$.

We conducted a secondary analysis of this initial cohort with the objective of describing intraoperative and postoperative outcomes in patients who underwent exploratory laparotomy and intestinal resection. The secondary objective was to propose and implement intraoperative optimization management for postoperative outcome improvement in surgical these surgical settings.

\section{Methods And Materials}


A secondary analysis of patients who underwent exploratory laparotomy and intestinal resection was included in the initial study (1).

The study was declared to the National Commission for Computer Science and Liberties (CNIL) under registration number 2028257 v0 on 21 February 2017 and approved by the Ethics Committee of Necker under registration number 2017-CK-5-R1 on 21 March 2017.

The inclusion criteria were patients who underwent exploratory laparotomy or intestinal resection and aged less than 18 years old included in the initial study.

The exclusion criteria were patients who did not undergo exploratory laparotomy or intestinal resection and were aged more than 18 years old.

Patients were included retrospectively from 1 January 2014 to 17 May 2017.

Statistics were analyzed with XLSTAT 2020.4.1. software. Continuous variables were expressed as medians with ranges or means with standard deviations. Categorial variables were described in proportions.

\section{Results}

Table 1 illustrates general characteristics.

There were 54 patients with a median age of 15.5[0-172] months and a median weight of 6.4[1.4-42] kilograms. There were four (7.4\%), twenty-four (44.4\%), twenty-two (40.7\%) and four (7.4\%) American Society of Anesthesiologists grade 1, 2, 3 and 4 patients, respectively. Thirty-two (59.3\%) patients had an emergent intervention. Fourteen (25.9\%) patients had intraoperative and/or postoperative complications. Two (3.7\%) patients had intraoperative hemorrhagic shock. Two (3.7\%) patients had postoperative cardio-circulatory failure. Three (5.6\%) had postoperative respiratory failure. One (1.8\%) patient had postoperative multiple organ failure and neurologic failure. Three (5.6\%) patients had postoperative abdominal sepsis. One (1.8\%) patient had postoperative multiple organ sepsis and neuromeningeal sepsis. Four (7.4\%) patients had postoperative pulmonary sepsis. Two (3.7\%) had postoperative septicemia. Six (11.1\%) patients had reoperations. Seventeen (31.5\%) patients had intraoperative transfusion with packed red blood cells (PRBCs) and/or fresh frozen plasma (FFP) and/or concentrated platelet units (CUPs). The mean preoperative and postoperative hemoglobin levels were $12.6 \pm 3.3 \mathrm{~g} / \mathrm{dL}$ and $11.3 \pm 1.9$ $\mathrm{g} / \mathrm{dL}$, respectively.

The median crystalloid and colloid volumes were 1287.5[60-3100] $\mathrm{ml}$ and 0[0-1000] $\mathrm{ml}$, respectively.

The median length of intensive care unit stay (LOSICU) was 5[0-77] days. The median length of hospital stay (LOS) was 7[0101] days. The median total length of hospital stay (TLOS=LOSICU+LOS) was 15[4-178] days. The median length of mechanical ventilation (LMV) was 0[0-28] days.

The in-hospital mortality rate was $3.7 \%$ in two patients. All patients with fatal outcomes had a comorbidity, namely, congenital heart disease, one patient had a laparotomy for volvulus, one patient had an intestinal resection, and all were managed on an emergency basis. One patient died on postoperative day 63 , and the second patient died on postoperative day 75 . Table 2 illustrates the characteristics of patients with fatal outcomes.

Table 3 illustrates surgery.

Thirty-seven (68.5\%) patients underwent intestinal resection, nine (16.7\%) underwent exploratory laparotomy, and eight (16.8\%) underwent laparotomy for volvulus.

Table 4 illustrates the co-morbidities. 
The most common comorbidities were congenital coagulation disorders in ten (18.5\%) patients, congenital heart disease in four (7.4\%) patients, necrotizing enterocolitis in four (7.4\%) patients, cancer in three (5.6\%) patients, Hirschsprung's disease in three (5.6\%) patients and hepatic failure, intestinal pseudoocclusion, neurofibromatosis, and preterm births in two (3.7\%) patients.

\section{Discussion And Conclusion}

The rate of patients with intraoperative and/or postoperative complications in this secondary analysis was comparable to that in the initial cohort. The results of this secondary analysis highlight that morbidity in patients who underwent exploratory laparotomy and intestinal resection is high. Intraoperative optimization with goal-directed therapies could contribute to upgrading postoperative outcomes in these surgical settings $(11,12,13,14,15,16,17,18,19,20,21)$. Similar conclusions have been drawn in major surgical settings and where goal-directed therapies need to be developed and applied systematically to improve postoperative outcomes $(22,23,24,25)$.

Intraoperative goal-directed therapies need to be developed and included in these surgical settings for intraoperative and postoperative optimization.

\section{Declarations}

Conflicts of Interest: The author declared no conflicts of interest.

Funding: None

Author contributions: Claudine Kumba conceptualized and designed the study and drafted the initial manuscript. She designed the data collection instruments, collected data, carried out initial and final analyses.

Ethics Approval: This study received approval from the Ethics Committee of Necker on 21 March 2017 under registration number 2017-CK-5-R1 and waived patient consent.

\section{References}

1) Kumba C, Cresci F, Picard C et al (2017) Transfusion and Morbi-Mortality Factors: An Observational Descriptive Retrospective Pediatric Cohort Study. J Anesth Crit Care Open Access 8(4): 00315. DOI :10.15406/jaccoa.2017.08.00315.

2) Kumba C, Lenoire A, Cairet P, Dogaru-Dedieu E, Belloni I, Orliaguet G. Is Transfusion an Independent Risk Factor of Postoperative Outcome in Pediatric Orthopedic Surgical Patients? A Retrospective Study. J Emerg Med Critical Care 2018 ; 4(2) :7. DOI: $10.13188 / 2469-4045.1000018$.

3) Kumba C, Querciagrossa S, Blanc Thomas, Treluyer JM. Transfusion and Postoperative Outcome in Pediatric Abdominal Surgery. J Clin Res Anesthesiol 2018;1(1):1-8. 
4) Kumba C, Taright H, Terzi E, Telion C, Beccaria K, Paternoster G, Zerah M, Bustarret O, Jugie M, Rubinsztajn R, Treluyer JM. Blood Product Transfusion and Postoperative Outcome in Pediatric Neurosurgical Patients. EC Anaesthesia 2018; 4(8) : 288298.

5) Claudine Kumba. Preterm Infants in Major Abdominal Surgery and Postoperative Outcome. Research Square 30 June 2021. DOI: https://doi.org/10.21203/rs.3.rs-669064/v1.

6) Kumba C. Postoperative Outcome in Non-Preterm Infants Under One year Old in Non-Cardiac Surgery. Preprint from Research Square, 21 Jun. DOI: 10.21203/rs.3.rs-638904/v1 PPR: PPR359566

7) Claudine Kumba. "Children Aged between 1 and 3 Years in Noncardiac Surgery and Postoperative Outcome". EC Paediatrics 10.6 (2021): 67-74.

8) C. Kumba. Postoperative outcome in children aged between 3 and 6 years in abdominal surgery, neurosurgery and orthopedics. Pediatric Anesthesia and Critical Care Journal 2021;9(1):43-47 doi:10.14587/paccj.2021.7

9) Claudine Kumba. Postoperative Outcome in Children aged between 6 and 10 years in Major Abdominal Surgery, Neurosurgery and Orthopedic Surgery. Research Square 30 June 2021.

DOI: https://doi.org/10.21203/rs.3.rs-669076/v1.

10) Kumba C. Major Abdominal Surgery, Neurosurgery, Orthopedic Surgery in Children aged between 10 and 18 years and Postoperative Outcome. SOJ Pedia Clin Neonato. 2021;1(2):1-7.000509.

11) Tibby SM, Durward A, Murdoch IA. Are transoesophageal Doppler parameters a reliable guide to paediatric haemodynamic status and fluid management? Intensive Care Med 2001;27 (1):201-5.

12)Murdocc IA, Marsh MK, Tibby SM, McLuckie A. Continuous Haemodynamic Monitoring in Children: Use of Transoesophageal Doppler. Acta Paediatr 1995; 84(7):761-4.

13)Weber T, Wagner T, Neumann K, Deusch E. Low predictability of three different noninvasive methos to determine fluid responsivenne in critically ill children. Pediatr Crit Care Med 2015; 16 (3): e89-94. doi: 10.1097/PCC.0000000000000364. 
14) Gan H, Cannesson M, Chandler JR, Ansermino JM. Predicting fluid responsiveness in children: a systematic review. Anest Analg 2013; 117:1380-92.

15) Pereira de Souza Neto E, Grousson S, Duflo F et al. Predicting fluid responsiveness in mechanically ventilated children under general anaesthesia using dynamic parameters and transthoracic echocardiography. British Journal of Anaesthesia 2011; 106 (6):856-64

16) Kumba C (2020) Physiology Principles Underlying Goal Directed Therapies in Children. Res Pediatr Neonatol. 4(4).RPN.000591.2020.Doi/10.31031/RPN.2020.04.000591.

17) Kumba C (2020) Rationale of Goal Directed Therapies in Children. Adv Pediatr Res 7:42.

Doi:10.35248/2385-4529.20.7.42.

18) Kumba C (2020) Goal directed fluid and hemodynamic therapy and postoperative outcomes in children: Value of transthoracic echocardiographic aortic blood flow peak velocity variation: A multi-centre randomized controlled trial protocol. Adv Pediatr Res 7:35. DOI: 10.35248/2385-4529.20.7.35.

19) Kumba C, Willems A, Querciagrossa S et al. A Systematic Review and Meta- Analysis of Intraoperative Goal Directed Fluid and Haemodynamic Therapy in Children and Postoperative Outcome. J Emerg Med Critical Care 2019;5(1):1-

9. DOI: $10.13188 / 2469-4045.1000020$.

20) Kumba C (2019) “Do Goal Directed Therapies Improve Postoperative Outcome in Children? (Perioperative Goal Directed Fluid and Hemodynamic Therapy; Transfusion goal directed therapy using viscoelastic methods and enhanced recovery after surgery and Postoperative outcome): A Study Research Protocol”. Acta Scientific Paediatrics 2(7) :17-

19.Doi:10.31080/ASPE.2019.02.0094.

21)Kumba C, Querciagrossa S, Harte C, Willems A et al. A Systematic Review and Meta-analysis of Goal Directed Intra-Operative Transfusion Protocols Guided by Viscoelastic Methods and Perioperative Outcomes in Children. Int J Recent Sci Res 2019 ; 10 (03), pp. 31466-31471.

22)Claudine Kumba. Liver Transplantation in Children and Impact of Intraoperative Goal-Directed Therapies on Postoperative Outcome. Research Square 23 July 2021.

DOI: https://doi.org/10.21203/rs.3.rs-744584/v1. 
23) Claudine Kumba. Scoliosis in Children: Impact of Goal Directed Therapies on Intraoperative and Postoperative Outcomes. Research Square 31 July 2021.

DOI: https://doi.org/10.21203/rs.3.rs-765785/v1.

\section{4) Claudine Kumba. Patient Blood Management in Craniosynostosis Surgery. Research Square 02 August 2021. DOl: https://doi.org/10.21203/rs.3.rs-774234/v1.}

25) Claudine Kumba. Intraoperative Goal-Directed Therapies in Femoral and Pelvic Osteotomies in Children and In-Hospital Postoperative Outcomes. Research Square 03 August 2021. DOI: https://doi.org/10.21203/rs.3.rs-777279/v1.

26) Claudine Kumba. Neuroblastoma in Children: Intraoperative Goal Directed Therapy, Intraoperative And Postoperative Outcomes. Research Square 6 August 2021. DOI: https://doi.org/10.21203/rs.3.rs-785499/v1.

\section{Tables}




\begin{tabular}{|c|c|}
\hline Characteristic & $\mathrm{N}=54$ \\
\hline Median age [range] in months & $15.5[0-172]$ \\
\hline Median weight [range] in kilograms & $6.4[1.4-42]$ \\
\hline ASA I n (\%) & $4(7.4)$ \\
\hline ASA II n (\%) & $24(44.4)$ \\
\hline ASA III n (\%) & 22(40.7) \\
\hline ASA IV n (\%) & $4(7.4)$ \\
\hline Emergency surgery $\mathrm{n}(\%)$ & $32(59.3)$ \\
\hline Elective surgery $n(\%)$ & 22(40.7) \\
\hline Re-operation n (\%) & $6(11.1)$ \\
\hline Patients with intra-operative and or postoperative complications (organ failure or sepsis) n (\%) & 14(25.9) \\
\hline Intraoperative hemorrhagic shock n (\%) & $2(3.7)$ \\
\hline Postoperative cardio-circulatory failure n (\%) & $2(3.7)$ \\
\hline Postoperative respiratory failure $\mathrm{n}(\%)$ & $3(5.6)$ \\
\hline Postoperative multiple organ failure $\mathrm{n}(\%)$ & $1(1.8)$ \\
\hline Postoperative neurologic failure $\mathrm{n}(\%)$ & $1(1.8)$ \\
\hline Postoperative abdominal sepsis $\mathrm{n}(\%)$ & $3(5.6)$ \\
\hline Postoperative multiple organ sepsis n (\%) & $1(1.8)$ \\
\hline Postoperative neuro-meningeal sepsis $\mathrm{n}(\%)$ & $1(1.8)$ \\
\hline Postoperative pulmonary sepsis $\mathrm{n}(\%)$ & $4(7.4)$ \\
\hline Postoperative septicemia n (\%) & 2(3.7) \\
\hline In-hospital mortality n (\%) & $2(3.7)$ \\
\hline Transfusion n (\%) & $17(31.5)$ \\
\hline Median packed red blood cells volume in $\mathrm{ml}$ [range] & $0[0-5]$ \\
\hline Median fresh frozen plasma volume in $\mathrm{ml}$ [range] & $0[0-2]$ \\
\hline Median concentrated platelet units [range] & $0[0-2]$ \\
\hline Mean preoperative hemoglobin levels \pm standard deviation in $\mathrm{g} / \mathrm{dL}$ & $12.6 \pm 3.3$ \\
\hline Mean postoperative hemoglobin levels \pm standard deviation in $\mathrm{g} / \mathrm{dL}$ & $11.3 \pm 1.9$ \\
\hline Median crystalloid volume in ml [range] & $1287.5[60-3100]$ \\
\hline Median colloid volume in ml [range] & $0[0-1000]$ \\
\hline Median length of intensive care unit stay in days [range] & $5[0-77]$ \\
\hline Median length of hospital stay in days [range] & $7[0-101]$ \\
\hline Median total length of hospital stay in days [range] & $15[4-178]$ \\
\hline Median total length of mechanical ventilation in days [range] & $0[0-28]$ \\
\hline
\end{tabular}


Table 1 General characteristics

Table 2 Patients with fatal outcome

\begin{tabular}{|lllllllll|}
\hline Surgery & $\begin{array}{l}\text { Age in } \\
\text { months }\end{array}$ & $\begin{array}{l}\text { ASA } \\
\text { score }\end{array}$ & $\begin{array}{l}\text { Co- } \\
\text { morbidities }\end{array}$ & $\begin{array}{l}\text { Intra- } \\
\text { operative } \\
\text { complications }\end{array}$ & $\begin{array}{l}\text { Postoperative } \\
\text { outcome }\end{array}$ & $\begin{array}{l}\text { Delay of } \\
\text { in- } \\
\text { hospital } \\
\text { mortality } \\
\text { in days }\end{array}$ & Emergency & Transfusion \\
\hline $\begin{array}{l}\text { Laparotomy } \\
\text { for volvulus }\end{array}$ & 1 & 4 & $\begin{array}{l}\text { Congenital } \\
\text { Heart } \\
\text { Disease }\end{array}$ & 0 & $\begin{array}{l}\text { Multiple } \\
\text { Organ Sepsis }\end{array}$ & 75 & 1 & No \\
\hline $\begin{array}{l}\text { Intestinal } \\
\text { Resection }\end{array}$ & 0 & 3 & $\begin{array}{l}\text { Congenital } \\
\text { Heart } \\
\text { Disease }\end{array}$ & 0 & $\begin{array}{l}\text { Multiple } \\
\text { Organ Failure } \\
\text { and Neuro- } \\
\text { meningeal } \\
\text { sepsis }\end{array}$ & 63 & 1 & 1 \\
\hline
\end{tabular}

Table 3 Surgery

\begin{tabular}{|ll|}
\hline Surgery & Number of (\%) \\
\hline Intestinal resection & $37(68.5)$ \\
\hline Exploratory laparotomy & $9(16.7)$ \\
\hline Laparotomy for Volvulus & $8(14.8)$ \\
\hline
\end{tabular}

Table 4 Co-morbidities 


\begin{tabular}{|ll|}
\hline Co-morbidity & Number of patients(\%) \\
\hline Bronchodysplasia & $1(1.8)$ \\
\hline Cancer & $3(5.6)$ \\
\hline Congenital coagulation disorder & $10(18.5)$ \\
\hline Congenital heart disease & $4(7.4)$ \\
\hline Crohn's disease & $1(1.8)$ \\
\hline Duodenal atresia & $1(1.8)$ \\
\hline Former preterm & $1(1.8)$ \\
\hline Hepatic failure & $2(3.7)$ \\
\hline Hepatoblastoma & $1(1.8)$ \\
\hline Hirschprung & $3(5.6)$ \\
\hline Intestinal pseudo-occlusion & $2(3.7)$ \\
\hline Necrotizing enterocolitis & $4(7.4)$ \\
\hline Neurofibromatosis & $2(3.7)$ \\
\hline Polymalformation syndrome & $1(1.8)$ \\
\hline Polytrauma & $1(1.8)$ \\
\hline Pre-term & $2(3.7)$ \\
\hline Pre-term+Necrotizing enterocolitis & $2(3.7)$ \\
\hline Transplantation & $1(1.8)$ \\
\hline
\end{tabular}

